\title{
Tales from the thousand lakes: Placing the creative network of metal music in Finland
}

ARTICLE in ENVIRONMENT AND PLANNING A · JANUARY 2014

Impact Factor: $1.69 \cdot$ DOI: $10.1068 / a 130020 p$

1 AUTHOR:

Teemu Makkonen

University of Surrey

21 PUBLICATIONS 17 CITATIONS

SEE PROFILE 
Teemu Makkonen, 2015. The definitive, peer-reviewed and edited version of this article is published in Environment and Planning A, volume 46, issue 7, pages 1586-1600, year 2015, DOI: $\underline{10.1068 / a 130020 p}$

Tales from the thousand lakes: placing the creative network of metal music in Finland

Teemu Makkonen

Department of Border Region Studies, University of Southern Denmark

Alsion 2, DK-6400, Sønderborg, Denmark; e-mail: teemu@sam.sdu.dk

\begin{abstract}
Music in general and the music industry in particular have been understudied subjects in the field of geography. The relatively scarce amount of literature on music industries has concentrated its attention on companies operating inside the industry, and on popular music. There is a gap in the knowledge on the networking processes of individuals inside the music industry and the geographical dynamics of music genres. Thus, as a point of departure, this study focuses on the creative individuals of a distinct music genre, namely the bands and artists of the Finnish metal music genre, owing to the genre's international recognition and its importance in the Finnish economy and society. According to the analysis the metal bands in Finland tend to cluster in the largest cities. There are, however, some exceptions-very small municipalities (in terms of population) with a fair number of metal bands. Still, the capital Helsinki is the most prominent
\end{abstract}


cluster of metal music in Finland. A further social network analysis reveals that the metal music cluster of Helsinki has a network of short average path length and a high degree of clustering. In other words, the members of the network function in close collaboration with each other. This notion was also verified by mapping the joint-career path of the most prolific (connected) individuals inside the network.

Keywords: Cluster, Creativity, Cultural industry, Metal music, Network

\section{Introduction}

Music in general and other genres than popular music in particular have for long been rather neglected subjects in the field of geography (Connell and Gibson, 2004; Johansson and Bell, 2009; Kong, 1995). Still, the importance of metal music as an international brand and export product has been recognized in Finland. From being an oddity inside the Finnish music industry, since the days of national pioneers such as Hanoi Rocks, Sarcofagus and Stone in the 1970s and 1980s, the genre has become increasingly popular from the 1990s onwards. This development has coincided with the establishment of the Finnish record label Spinefarm Records, which has had a major influence on the development of the Finnish metal music genre. In fact, according to the national billboards (IFPI Finland, 2013) of Finland, metal music nowadays accounts for a large share of domestic record sales and metal bands are among the top-selling Finnish artists in international markets. In the recent years this list has included such internationally known bands (they have also appeared in the U.S. Billboard charts, and tour globally) as Apocalyptica, Children of Bodom and Nightwish, as well as nationally oriented bands (bands performing in Finnish), namely Kotiteollisuus, Mokoma and Stam1na. Further examples of the mainstream support for the genre have been the 
nomination of Lordi for the 2006 Eurovision Song Contest (and their subsequent victory); the victory of Ari Koivunen, a heavy metal singer, in the 2007 season of the Finnish TV show "Idols", and the phenomenon described as "Children's Metal" in the form of Hevisaurus (and Sauruxet), who dress up as dinosaurs and perform child friendly metal songs. In conclusion, the national popularity and international recognition of the Finnish metal music genre render it an interesting topic for economic geography. Moreover, the fact that Finland has the highest concentration of metal bands per capita fits well with the purposes of social network analyses (Grandoni, 2012). Therefore, public media and Finnish embassies around the world are highlighting the image and economic impacts of Finnish metal music in their bulletins. In short, Finland is marketed as the Mecca or Promised Land of metal music (Friman et al, 2013). Still, there is an apparent lack of academic research on the subject.

There are, however, a few recent surveys exploring the structure of Finland's music economy. As can be seen from the figures of IFPI Finland (2013), the structure of the Finnish recorded music industry is organized into majors (large record labels) and independents (small record labels and independent musicians); the four largest record labels had a combined market share of ca. $80 \%$ in 2012. According to a survey by VAKA (2011), Finland's music industry is generally concentrated to the Finnish capital: about $75 \%$ of the Finnish musicians reside and circa $40 \%$ of the concerts take place in the Helsinki capital region. Similarly, about 30\% of the Finnish (metal) music record labels with geocoding information (including most of the biggest labels such as Spinefarm Records, EMI Music Finland and Warner Music Finland) are located in the Helsinki capital region (Encyclopaedia Metallum, 2013). The most important public intervention comes through the provision of adequate legal means for the protection and enforcement of intellectual property rights (Thorsby, 2002). However, the state, municipalities and foundations are also supportive via grants which 
amounted to approximately 15 million Euros in 2011, and to 2-3\% of the total income of Finnish musicians (Tolppanen and Tuomainen, 2012). According to recent questionnaire results (Teosto, 2012) it is possible to make a rather decent living out of music in Finland. Notwithstanding, the income fluctuates heavily on a year-to-year basis. Therefore, one might speculate that the high living costs, housing prices and rents in Helsinki (Statistics Finland, 2013) will averse musicians to residing elsewhere than in the Finnish capital, since contemporary digital technologies allow musicians to choose their living places more freely (Hracs et al, 2011).

According to Watson et al (2009) studies in music and geography can be broadly categorized into three perspectives: 1 ) studies which have been concerned with the role of music in the social and cultural construction of place, space and identity 2) studies which have explored soundscapes, sonic environments and the performative aspects of music, and 3) a smaller number of geographical studies undertaken by economic geographers on the economics and spatiality of the music industry, as well as on the impacts of technological innovation on music sales and distribution. Music clusters or music industry have been closely studied as an agglomeration of record labels and associated enterprises (Scott, 1999; Watson, 2008) but rarely as a network of bands and artists. Moreover, whereas popular music (pop and rock) has been the subject of geographical research (Connell and Gibson, 2003; Krims, 2007), authors have paid little attention to the economic geography of metal music (Gross, 1990; Harris, 2000).

Therefore, the purpose of this paper is to fill a distinct gap in literature by discussing the geographical, economic and social implications of metal music as it refers to Finnish bands and individual artists. This viewpoint of concentrating on one specific genre of music is supported by the notion that describing music industry as a homogenous unit, with shared objectives and 
interests, is outdated, simplistic and an inaccurate portrayal of the organisational structure of the global music economy (Williamson and Cloonan, 2007). Having said this, it is fair to admit that describing metal music as one coherent entity is also a generalisation in itself and does not fully do justice to the whole spectrum of different styles inside the (broad) music genre (Kahn-Harris, 2007).

This paper utilises methods from geographical and social network analyses. Following Henry and Pinch (2000), and their influential article on the knowledge community of Motor Sport Valley (Formula One racing), the paper explores the scale, character and geographical location of the Finnish metal music cluster. The specific aims of this paper are to: 1) outline the geographical distribution of metal bands in Finland and 2) explore the networked nature of the Finnish metal bands. Thus, the aim of the paper is to study whether the Finnish metal music genre is a typical or unique case of cultural industries in terms of its geographical patterns and networking structures in order to confirm (or challenge) the existing theory on clusters, creativity and networks.

\section{Clusters, creativity and networks: Music and the economy}

Since the works of Porter (1990) and Krugman (1991) scholarly debate has frequently turned its attention to the tendency of companies in certain industries to agglomerate, i.e., to cluster together. The basic argument behind this observed propensity is that even in a global economy, local assets (factor and demand conditions, infrastructure, related supporting industries, etc.) can constitute an enduring competitive advantage, enhanced by the constant and coexistent cooperation and competition between the enterprises in a certain cluster, which distant rivals cannot match. These clusters are sustained through the existence of external economies, 
increasing returns and lowered transportation costs. In essence, clusters facilitate frequent encounters through which networks are forged. As it is advantageous for interacting agents to be located close to each other (Cummins-Russell and Rantisi, 2012) obvious spaces for clusters are the largest cities. The same kind of reasoning can be found in the works of Florida (2002), further elaborated directly in terms of the music industry (Florida and Jackson 2010; Florida et al, 2010) concerning the concentration of what he termed the 'creative class' into cities with vibrant and tolerant living environments. The views on the dynamics of cultural industry clusters can be integrated with the Florida-type tendency of creative individuals wanting to live in large cities, which present abundant employment opportunities, concentration of other artists and increased demand. This offers a plausible explanation for the agglomeration processes observed in the case of cultural industries (Lorenzen and Frederiksen, 2008).

Further elaborations on the topic have led to interesting new developments regarding the subject: notably, according to Asheim et al (2007), it is precisely the creative industries that tend to agglomerate in cities, whereas for other industries this is not a necessity. It is because the unique (symbolic) knowledge base of creative industries relies heavily on tacit knowledge, local buzz (nondeliberate knowledge and information sharing propensities) and face-to-face communications to which cities provide the best and most intensive means of access and opportunities. Whereas codified knowledge (more important for engineering and science industries) can be expressed in messages and easily transferred with communications technologies, tacit knowledge is hard to articulate or codify. Sharing tacit knowledge, thus, requires physical proximity because practical skills that embody tacit knowledge are impossible to express in numbers, text or formulas (Asheim and Hansen, 2009; Asheim et al, 2007). This discussion on knowledge bases has brought forth an 
interesting way to look at the music industry as a knowledge community providing a good example of the exchange of tacit knowledge (Cummins-Russell and Rantisi, 2012; Klein, 2011).

Accordingly, evidence points towards a conclusion that cultural industries tend to cluster, in a traditional Porterian sense, to benefit from external economies of scale and increasing returns, as do traditional manufacturing industries (Belussi and Sedita, 2008)-but with a heavy emphasis on cities (Power, 2002; 2003). Still, global networks and linkages designated as pipelines (Bathelt et al, 2004) are extremely important in the development and success of local clusters, likewise in the music industry. These networks and linkages represent how the music industry interacts socially and how knowledge is passed around (Brown et al, 2000). Drawing from the notions discussed above, the music industry can be viewed as a dichotomy. On the one hand, it is a highly localised cultural-product industry that draws from a local creative milieu and cultural forms, and has a tendency to agglomerate in urban areas; whereas on the other hand, it is a global business and distribution system dominated by a shrinking number of global media giants (Brown et al, 2000; Power and Hallencreutz, 2002). However, it would be wrong to think that the music industry is just about these global giants. On the contrary, there is a large pool of smaller (local) music companies, such as Spinefarm Records in Finland (Power and Hallencreutz, 2007). Moreover, the music industry is constantly under change due to technological innovations (Leyshon, 2001; 2009). Thus, the contemporary enhanced role of digital technologies (e.g. Internet downloading and peer-topeer file sharing) has challenged the entrenched power of the major record labels (Hracs, 2012).

Still, in line with the aforementioned theoretical contributions, Watson (2008) has demonstrated with empirical data on London's recorded music industry that although knowledge transfer within the industry occurs simultaneously across multiple geographical scales, these non-local scales 
offer only a partial substitute for geographical proximity. This is because the non-local connections do not provide the same scope for trust as frequent face-to-face contacts inherent in urban settings. The strong concentration of music industry into a few large urban centres, with few exceptions such as tourist destinations, is also evident in the case of the United States of America (Florida and Jackson, 2010; Florida et al, 2010; Scott, 1999). Basically, musicians have a considerable amount of freedom to locate away from the infrastructure needed to commercialize recorded music (a trend likely to accelerate due to the ease of file sharing) but they still tend to cluster (although loosely) around the recording industry (Florida et al, 2010). Accordingly, data from a close reference point for Finland-Sweden-have shown that cultural industries have a high propensity to agglomerate, having a strong attraction to urban areas (Power, 2002). Similarly, the top Finnish municipal concentrations of cultural industries are in the largest Finnish cities of Helsinki, Espoo, Tampere and Turku (Power, 2003).

Accordingly, Kloosterman (2005) has noted that music genres are embedded in places. Kloosterman labels this process the virtuous circle of a city making music and music making a city, and describes how cities with a vibrant music scene of this type are characterized by a concentration of highly talented musicians. Moreover, these cities have the institutional fabric (media, record labels, concert venues, music services, etc.) needed to support and sustain the creation of music. Therefore, other talented musicians from elsewhere will move there to compose music and find an audience for it. Examples of these highly spatialised genres include country music heavily concentrated in Nashville (Kloosterman, 2005), grunge in Seattle (Negus, 1996), Dixieland jazz in New Orleans and motown in Detroit (Florida et al, 2010). Thus, evidence on the agglomeration of the music industry seems to point towards a conclusion that large cities are in an advantageous position vis-à-vis smaller cities. Still, even small cities can thrive in the 
context of a particular music genre (Gibson and Davidson, 2004; Kloosterman, 2005). Moreoveras stated by Hracs et al (2011)-due to digital technologies contemporary musicians enjoy a greater freedom in following their locational preferences outside larger cities. Therefore, independent musicians who operate without the label infrastructure including record labels and studios may consider that smaller locations that are affordable in terms of living costs, housing prices and rents are more attractive.

The views on the importance of the size of the city are further discussed by Braunerhjelm (2009), who has stated that in order to fulfil the requirements for a successful, more culturally oriented cluster, a city may have an advantage in being sufficiently small for a high degree of connectivity: everybody knows everybody. One reason for this is that the respective agents often work with many various projects, as well as hold multiple roles and positions within the cluster, and are likely to work together on several occasions. At the same time, a city has to be sufficiently large to attract the agents important for the existence and development of a cluster. According to Braunerhjelm (2009) it thus seems that medium sized cities, such as Stockholm and possibly Helsinki, might in fact have a competitive advantage in developing and sustaining cultural industry clusters. Similarly, Helsinki has been frequently esteemed globally as one of the most attractive cities for the creative class (Kepsu and Vaattovaara, 2008).

As stated by Ter Wal and Boschma (2009) social network analysis has a great potential to enrich the literature on clusters and question its underlying assumptions. Accordingly, the music industry offers an interesting case for social network analysis due to its project-based nature resulting in a networked structure for the music community (Cummins-Russell and Rantisi, 2012). Therefore, the "everybody knows everybody" statement has been elaborated through close analyses with social 
network analysis tools vis-à-vis the music industry in general (e.g. Belussi and Sedita, 2008) and distinct music genres (e.g. Gleiser and Danon, 2003) in particular. Essentially, as skilfully summarised by Lorenzen and Täube (2008), two key observations can be gleaned from the literature on social networks. Firstly, a social network with a short average path length (the average number of edges between any two agents in the network) has high social trust (social capital) and is good for the transmission of new practices, as its members can easily reach each other. Secondly, a social network with short path lengths as well as a high degree of clustering (density of its interconnectedness) may block new entries. According to earlier studies (Belussi and Sedita, 2008; Lorenzen and Täube, 2008) cultural industries seem to have networks of short path lengths and a high degree of clustering. These concepts motivate the aim of this paper to study whether the same kind of connectivity can be detected inside the Finnish metal music genre. Similarly, given the recent developments in digital technologies, the question whether metal bands are still concentrated to the larger Finnish cities is topical.

\section{Data and study design}

The geographical distribution of Finnish metal bands was investigated here according to the database of Encyclopaedia Metallum (2013). There were circa 2,950 entries on Finnish metal bands: bands in demo stage, active bands with recording contracts, independent bands without recording contracts and former "retired" bands. Approximately 2,600 had the geocoding information on their hometown or in some cases hometowns in the database at the moment of data collection. If there were multiple hometowns the bands were divided between these locations with a coefficient of 0.5 . The database features information on band members, i.e., artists (present, former and guest musicians). This information was utilized to outline a general 
picture of the network, links between different metal bands according to their band members and furthermore, the joint-career path illustration. The decision to use the data from the Encyclopaedia Metallum (2013) was made on the basis of its coverage: it is by far the most extensive online database on Finnish metal bands (e.g., the database of Metal from Finland [2013] consists of circa 900 Finnish metal bands). Similarly, the geocoding information (home town/region) seems to be missing from virtually all other metal music databases.

Firstly, the geographical mapping exercise followed the methodology presented in the works of Power (2002; 2003) to illustrate Finnish metal music clusters in absolute numbers. Similarly, drawing from economic base analysis, it is worthwhile to study the concentration of metal bands in Finland in terms of location quotients. The location quotients (LQ) are as follows (Equation 1):

$$
L Q=\frac{b_{i} / p}{B_{i} / P}
$$

where $b_{i}$ is the number of metal bands in municipality $i$, whereas $p$ refers to the population in the municipality, which was used as an estimate of the number of bands in other music genres since data for bands playing genres other than metal music were unavailable. Accordingly, $B_{i}$ refers to the total number of Finnish metal bands and $P$ to the total population of Finland. A location quotient higher than 1 indicates a higher than average concentration (Power, 2003). Statistics Finland (2013) was used as the data source for population statistics.

Secondly, the network of bands in the most prominent Finnish metal music cluster was visualised through the connectivity between artists belonging to multiple bands pursuant to the analyses by Watson (2012) on the global recorded music industry. In the analysis, social network analyses 
methods were applied (see Scott, 2013; Watts and Strogatz, 1998): the network was portrayed through average path length and the degree of clustering. Average path length is calculated by defining the shortest paths between all pairs of bands, summing them up and dividing them into an average. The average path length $\left(I_{G}\right)$ can be formulated as follows (Equation 2 ):

$$
l_{G}=\frac{1}{n *(n-1)} * \sum_{i, j} d\left(v_{i}, v_{j}\right)
$$

where $n$ stands for the number of bands in the network $G$, whereas $d\left(v_{i}, v_{j}\right)$ expresses the shortest path length (number of edges, i.e., links) between bands $v_{i}$ and $v_{j}$. The average path length was used here to indicate how far apart any two nodes are on average. Accordingly (see Scott, 2013; Watts and Strogatz, 1998), the degree of clustering of the network was calculated as the average of clustering coefficients of individual bands. The clustering coefficients $\left(C_{i}\right)$ of a band can be expressed as follows (Equation 3):

$$
C_{i}=\frac{2 e_{i}}{k_{i}\left(k_{i}-1\right)}
$$

where $e_{i}$ is the number of connections (edges, i.e., links) between band $i$ and other bands directly connected to it, as well as between these other bands. $K_{i}$ refers to the number of bands directly connected to the band $i$. The degree of clustering indicates the ratio between real links and the maximum number of possible links in a network. If all bands would be connected to every other band, the network would be completely connected, i.e., a clique. However, this is highly unlikely. In comparison, the average path length and degree of clustering of the real social network was benchmarked against that of an equivalent random graph model (see Erdős and Rényi, 1959; Gilbert, 1959; Newman et al, 2002) generated following the $G(n, p)$ model, where $n$ is the number 
of nodes and $p$ is the probability with which each edge is included in the graph. In essence, the real social networks should have average path lengths of roughly the equal magnitude but higher degrees of clustering than pure random graph models, which suggests that there are truly social forces at work in the network (Newman et al, 2002).

Thirdly, the analysis concluded with tracking the joint-career path (cf. Henry and Pinch, 2000) of a particularly prolific team of musicians within the limits of the Finnish metal genre. This approach was based on the notion that although artistic creators are individualistic according to the traditional view, in discussing bands it is relevant to label their efforts as a product of group artistic creativity. The reason is that the outcome (a record, gig or a musical show) includes the joint efforts of many talented individuals (Cohendet et al, 2009; Simonton, 2004). Therefore, it is important for individual metal artists to be well connected. Degree centrality (the number of links that an artist in a band has with other bands) was used here to identify the most connected individuals.

Naturally, there are limitations to this study. The database used to derive the data concerning the metal bands in Finland operates on a voluntary basis and can be considered extensive but not all inclusive. Firstly, there was no geocoding information regarding a large number of Finnish metal bands. Secondly, due to the use of stage names and aliases (the ones linked to real names in the database were taken into account) network analysis cannot be performed with one-hundred per cent accuracy. Thirdly, the trustworthiness of the database cannot be double checked from other sources as the universe of Finnish metal bands in its entirety is unobservable: the database actively excludes some subgenres of metal music, the number of bands in their demo stage is nearly impossible to estimate from other sources, and retired bands left out from the database are 
hard to trace down even if they have had a record deal. Moreover, the fact that the database only includes the links of playing and touring with the same band leaves other forms of networking (sharing a record label or a booking agent, etc.) out of the scope of this study. Still, having said this, the database used here still is the best available source of data on metal bands in Finland. In relation to location quotients, the unavailability of data on music genres other than metal remains a limitation. Additionally, it is acknowledged here that relying solely on quantitative data and analysis cannot fully explain the locational choices made by the individuals within the Finnish metal music genre (Hracs et al, 2011). However, taking into account the rich literature published earlier on the clustering of cultural and music industries, it is fair to say that the results presented below can be said to be plausible.

\section{Results}

Geographical analysis

In Finland, metal bands geographically cluster in the largest cities: Helsinki, Tampere, Oulu, Turku, Jyväskylä, Lappeenranta, Lahti, Kuopio, Vantaa, Espoo and Joensuu host the highest concentrations (Figure 1). Of these, Helsinki ranks in a league of its own with more than twice the number of metal bands than is involved in the second largest concentration of Tampere. The picture is even more marked when considering the number of bands located in the close vicinity of the national capital: in addition to Helsinki, the other nearby cities, including Espoo and Vantaa, host a prominent number of metal bands. This has at least partly to do with the fact that record labels, concerts and studios are also concentrated in the Helsinki capital region (Encyclopaedia Metallum, 2013; VAKA, 2011). For example, according to the Encyclopaedia Metallum (2013) about $46 \%$ of the Finnish metal bands under the Spinefarm Records label, compared to $16 \%$ of all 
Finnish metal bands, are based in Helsinki. This indicates that, indeed, musicians with a record deal seem to be more prone to locate to the larger cities than independent musicians. Moreover, proximity to international markets (including e.g. Germany, one of the world's largest consumers of metal music culture) is surely a significant factor explaining the locational preferences of Finnish musicians and the reason they favour the Helsinki capital region. The other mentioned cities are also regional centres in terms of population (markets) and economic activities. Accordingly, the migration flows of artists and bands inside the Finnish metal genre are directed from smaller municipalities to larger cities, in particular to Helsinki, Tampere and Jyväskylä. This correlates with the overall migration trends in Finland.

<Figure 1. about here>

When the number of metal bands is normalized in relation to the population, i.e., measured with the modified location quotients, the picture is more evenly dispersed with many small localities, such as Kuortane, Laitila and Kitee ranking high with a small population but a fair number of metal bands (Figure 1). Still, many of the larger cities, including Lappeenranta, Jyväskylä, Oulu and Lahti are among the top municipalities even when measured in location quotients. In contrast, Helsinki has only a mediocre (but higher than average) score in terms of location quotients. Nonetheless, it is fair to say that Helsinki, with its absolute number of bands exceeding others by far, is the most prominent location for metal bands in Finland. Therefore, this paper shall proceed with exploring the network structure of the most prominent Finnish metal music cluster, Helsinki. 
Social network analysis and joint-career paths

At the moment of data collection, the database of Encyclopaedia Metallum (2013) included information on approximately 2,650 artist-band pairs from the more than 400 metal bands and almost 1,950 individual artists in Helsinki (although some of the bands' entries lacked information concerning their members). These pairs were used as a basis for the calculations of links between the bands, i.e., the nodes. Naturally, as networks cross the boundaries of regions (Ter Wal and Boschma, 2009), there are links between Helsinki and other municipalities in Finland but these where left out of the analysis to simplify the process, as the aim was to concentrate on the metal music cluster of Helsinki. From the number of artists and artist-band pairs it is easy to see that the metal music cluster (network) in Helsinki follows the principles of power laws in scale-freenetworks (Barabási, 2002; Barabási and Albert, 1999). Most bands have no or only a few links, whereas there are a few hubs-highly connected nodes - in the network, i.e., bands (Figures 2-3). This was expected, as it is unlikely that a network would encompass all actors in a cluster (Ter Wal and Boschma, 2009).

<Figure 2. about here>

$<$ Figure 3. about here $>$

The most connected bands (the highest degree centrality; Figure 3, inner circle) offer interesting insights into the evolution of social networks (Barabási, 2002; Barabási and Albert, 1999). The most connected band, Barathrum, was established already in 1990 in Kuopio whence it later relocated itself to Helsinki. Since the band has existed for decades, an extensive number of artists 
has performed with it over the years and, thus, connected it to a vast number of other bands via these links. The opposite tendency is exemplified by a highly connected band called Lakupaavi, which was active only during one recording session in 2005. However, the band was a project of artists mostly involved in another highly connected band, Moonsorrow, which thus explains this anomaly. Therefore, it may be suggested that the network has evolved through preferential attachment and growth, where new bands link to already well-connected, established bands: new bands gain in having a well-known artist (contributing to publicity, know-how, etc.) in their roster, while the acclaimed artists are also keen on establishing their own musical projects (bands). Interestingly, all three bands mentioned and other highly connected bands, Ajattara and Soulgrind, practice extreme subgenres of metal described in the database (Encyclopaedia Metallum, 2013) as black, death or doom metal. It can be thus claimed that bands in these subgenres are more densely connected than the more mainstream metal bands. This result is a clear example of homophily-actors in a network partner with similar actors (Ter Wal and Boschma, 2009). Bands with no links are mainly still in their demo stage or have never reached a record deal and eventually split up (Figure 3, outer ring). In general, the lack of links of young musicians/bands is, hence, simply explained by the fact that they have not had the time to network: as bands mature their collaboration network expands. However, it has also been noted that an already existing dense network might block new younger bands from establishing links (Lorenzen and Täube, 2008).

According to the analysis, it can be stated that the average path length of the network is short $\left(I_{G}=\right.$ 4.104) and the degree of clustering is quite high $\left(C_{i}=0.219\right)$. When compared to a number of equivalent random graph models constructed (and a number of random graph models with a higher numbers of links), the average path lengths were equally short but the clustering coefficient 
of the real network was always significantly higher than of the ones produced by pure randomness. Therefore, it can be claimed that there are significant social forces at work in the network of metal bands in Helsinki (cf. Newman et al, 2002).

Drawing from social network analysis, this paper moves on to a closer examination of some of the more prolific bands (with the highest degree centrality) and the most connected musicians in order to map the possible joint-career path of these highly connected individuals. Ostensibly, the most connected musicians in the dataset of metal bands from Helsinki are all from the same (naturally highly connected) band-Moonsorrow. The musicians are Henri Sorvali, guitarist and keyboardist; Janne Perttilä, (live) guitarist; and Marko Tarvonen, drummer (Figure 4).

$<$ Figure 4. about here $>$

The illustration of a joint-career path shows that musicians in the metal music cluster of Helsinki frequently work with common projects, i.e., bands. This underlines the importance of social ties and shared working pasts in cultural industries: it can be claimed that musicians of the metal music cluster in Helsinki are likely to collaborate with members of the network they already know. Moreover, the results indicate what can be termed triadic closure, that is, partners of partners become partners among themselves (Ter Wal and Boschma, 2009).

\section{Discussion and conclusions}

The geographical analysis performed in this paper corresponds well to earlier theoretical contributions on creative individuals and knowledge bases (Asheim et al, 2007; Florida, 2002), and 
empirical studies concentrating on cultural and music industries in the Nordic countries as well as the United States (Florida and Jackson 2010; Florida et al, 2010; Power 2003). In Finland metal bands tend to cluster in the largest cities and in particular the Helsinki capital region. The results are more evenly dispersed when measured in location quotients but in line with the overall picture of a strong concentration to larger city regions. There are a few exceptions of small municipalities with a very small population but a fair number of metal bands. Therefore, it can be claimed that bands in the Finnish metal music genre are still located in close vicinity to the markets (customers, i.e., high population concentrations and access to global markets), record labels and concert venues. This despite the developments in digital technologies that gave rise to the relative freedom of locating to areas with lower living and housing costs (Hracs et al, 2011). An interesting topic for further studies would be to investigate the characteristics of networks in the smaller towns or municipalities with high location quotients. Moreover, comparable studies on other countries are highly welcome to test the concepts laid out in this paper in various geographical contexts.

As in the case of cultural industries explored by earlier studies (Belussi and Sedita, 2008; Lorenzen and Täube, 2008), the metal music cluster of Helsinki has a network of short average path length and a high degree of clustering. The results are also in line with those of earlier genre-specific studies (e.g. Gleiser and Danon, 2003) highlighting the notion that the networks within specific music genres are more close-knit compared to those within music in general, and the somewhat elusive popular music in particular (see DiMaggio, 2011). This means that the network is likely to exhibit strong social trust as its members are in close collaboration with each other. However, bands with no links generally have not yet succeeded in getting a record deal (or have no intention to do so). Thus, it may be said that the high degree of clustering might even block new entries in 
the form of metal bands with artists outside the current network. It seems that actors in a network partner with similar actors. Thus, it may also be suggested that bands within some subgenres of metal music are more connected than the more mainstream metal bands. Therefore, further analysis of different genres and subgenres of music may produce interesting insights into the clustering and networking characteristics of cultural industries.

The importance of social ties and intensity of close collaboration between individuals in the network of metal bands in Helsinki were further reinforced with an illustration of the joint-career path of the most highly connected musicians. The reasoning behind this exercise was based on the idea that recording an album and performing a gig includes the joint efforts of many talented individuals (Cohendet et al, 2009; Simonton, 2004). Thus, as proposed by Braunerhjelm (2009), artists do frequently collaborate through common projects with members of the network they already know. Moreover, the results indicate that partners of partners frequently become partners among themselves. This is likely to be the case in many other cultural industries as well. However, comparable analyses are required to fully understand the group artistic characteristics of individual sectors in other music genres and cultural industries.

In conclusion, this study is one of the first attempts to explore the geographically concentrated and networked nature of a distinct music genre, namely metal music. The data used involve some limitations and, admittedly, more comparable research is still needed. Still, the results presented here illustrate that the characteristics describing the geographical distribution (highly concentrated to the largest cities) and network structure (highly connected) of Finnish metal bands correlate with the principles postulated in earlier studies on social networks and therefore confirms the existing theory in many ways. Thus, the results presented here have wider relevance 
besides the specific case of Finnish metal music genre. It seems that the city size does play a role in relation to the intensity and importance of social networks, since in larger cities the existence of local creative networks is more marked. Still, whereas the general principles expressed when discussing knowledge bases and the collaboration patterns of creative industries-the heightened importance of city size in creating local buzz-seem to hold in the light of the evidence presented here, the fact that even small towns are shown to host prominent numbers of creative teams challenge stringent interpretations of large city size as a necessity for the emergence of successful creative localities. However, qualitative research is needed to unravel and confirm the suggested reasons behind the observed statistical results presented in this paper.

\section{Acknowledgements}

I am grateful for the editor and three anonymous reviewers for their constructive comments for improving the article.

\section{References}

Asheim B, Hansen H, 2009, "Knowledge bases, talents and contexts: on the usefulness of the creative class approach in Sweden" Economic Geography 85 425-442

Asheim B, Coenen L, Vang J, 2007, "Face-to-face, buzz and knowledge bases: sociospatial implications for learning, innovation and innovation policy" Environment and Planning C 25 655-670

Barabási A-L, 2002 Linked: The New Science of Networks (Perseus Publishing, Cambridge) Barabási A-L, Albert R, 1999, "Emergence of scaling in random networks" Science 286 509-512 
Bathelt H, Malmberg A, Maskell P, 2004, "Clusters and knowledge: local buzz, global pipelines and the process of knowledge creation" Progress in Human Geography 28 31-56

Belussi F, Sedita S, 2008, "The management of events in the Veneto performing music cluster: bridging latent networks and permanent organization", in Creative Cities, Cultural Clusters and Local Economic Development Eds. P Cooke, L Lazzaretti (Edward Elgar, Cheltenham) pp 237-257

Braunerhjelm P, 2009, "The genesis and evolution of the Stockholm music cluster", in New Directions in Regional Economic Development Eds. C Karlsson, Å Andersson, P Cheshire, R Stough (Springer, Berlin) pp 385-408

Brown A, O'Connor J, Cohen S, 2000, "Local music policies within a global music industry: cultural quarters in Manchester and Sheffield" Geoforum 31 437-451

Cohendet P, Grandadamab D, Simon L, 2009, "Economics and the ecology of creativity: evidence from the popular music industry" International Review of Applied Economics 23 709-722

Connell J, Gibson C, 2003 Sound Tracks: Popular Music, Identity and Place (Routledge, London)

Connell J, Gibson C, 2004, "World music: deterritorializing place and identity" Progress in Human Geography 28 342-361

Cummins-Russell T, Rantisi N, 2012, "Networks and place in Montreal's independent music industry" Canadian Geographer 56 80-97

DiMaggio P, 2011, "Cultural networks", in SAGE Handbook of Social Network Analysis Eds. J Scott, P Carrington (SAGE, Thousand Oaks) pp 286-300

Encyclopaedia Metallum, 2013, www.metal-archives.com/lists/FI (accessed on 26.2.2013)

Erdős P, Rényi A, 1959, "On random graphs" Publicationes Mathematicae 6 290-297

Florida R, 2002 The Rise of the Creative Class (Basic Books, New York)

Florida R, Jackson S, 2010, "Sonic city: the evolving economic geography of music industry" Journal of Planning Education and Research 29 310-321 
Florida R, Mellander C, Stolarick K, 2010, "Music scenes to music clusters: the economic geography of music in the US, 1970-2000" Environment and Planning A 42 785-804

Friman M, Korhonen E, Räikkönen M, 2013, "Music as the gate to Finnish culture" Interdisciplinary Studies Journal 2 164-169

Gibson C, Davidson D, 2004, "Tamworth, Australia's country music capital: place marketing, rurality, and resident reactions" Journal of Rural Studies 20 387-404

Gilbert E, 1959, "Random graphs" Annals of Mathematical Statistics 30 1141-1144

Gleiser P, Danon L, 2003, "Community structure in jazz" Advances in Complex Systems 6 565-573

Grandoni D, 2012, "A world map of metal bands per capita" www.theatlanticwire.com/entertainment/2012/03/world-map-metal-band-populationdensity/50521/ (accessed on 22.8.2013)

Gross R, 1990, "Heavy metal music: a new subculture in American society" Journal of Popular Culture 24 119-130

Harris K, 2000, "Roots: the relationship between the global and the local within the extreme metal scene" Popular Music 19 13-30

Henry N, Pinch S, 2000, "Spatialising knowledge: placing the knowledge community of Motor Sport Valley" Geoforum 31 191-208

Hracs B, 2012, "A creative industry in transition: the rise of digitally driven independent music production" Growth and Change 43 442-461

Hracs B, Grant J, Haggett J, Morton J, 2011, "A tale of two scenes: civic capital and retaining musical talent in Toronto and Halifax" Canadian Geographer 55 365-382

IFPI Finland, 2013, www.ifpi.fi/tilastot/ (accessed on 16.10.2013)

Johansson O, Bell T, 2009, "Where are the new US music scenes", in: Sound, Society and the Geography of Popular Music Eds. O Johansson, T Bell (Ashgate, Aldershot) pp 219-244 
Kahn-Harris K, 2007 Extreme Metal: Music and Culture on the Edge (Berg, Oxford)

Kepsu K, Vaattovaara M, 2008 Creative Knowledge in the Helsinki Metropolitan Area: Understanding the Attractiveness of the Metropolitan Region for Creative Knowledge Workers (University of Amsterdam, Amsterdam)

Klein R, 2011, "Where music and knowledge meet: a comparison of temporary events in Los Angeles and Columbus, Ohio" Area 43 320-326

Kloosterman R, 2005, "Come together: an introduction to music and the city" Build Environment 31 181-191

Kong L, 1995, "Popular music in geographical analyses" Progress in Human Geography 19 183-198

Krims A, 2007 Music and Urban Geography (Routledge, New York)

Krugman P, 1991 Geography and Trade (MIT Press, Cambridge)

Leyshon A, 2001, "Time - space (and digital) compression: software formats, musical networks, and the reorganisation of the music industry" Environment and Planning A 33 49-77

Leyshon A, 2009, "The Software Slump? Digital music, the democratisation of technology, and the decline of the recording studio sector within the musical economy" Environment and Planning A 41 1309-1331

Lorenzen M, Frederiksen L, 2008, "Why do cultural industries cluster? Localization, urbanization, products and projects", in Creative Cities, Cultural Clusters and Local Economic Development Eds. P Cooke, L Lazzaretti (Edward Elgar, Cheltenham) pp 155-179

Lorenzen M, Täube F A, 2008, "Breakout from Bollywood? The roles of social networks and regulation in the evolution of Indian film industry" Journal of International Management 14 $286-299$

Metal from Finland, 2013, www.metalfromfinland.com (accessed on 21.8.2013)

Negus K, 1996 Popular Music in Theory: An Introduction (Wesleyan University Press, Hanover) 
Newman M, Watts D, Strogatz S, 2002, "Random graph models of social networks" Proceedings of the National Academy of Sciences of the United States of America 99 2566-2572

Porter M, 1990 The Competitive Advantage of Nations (The MacMillan Press, London)

Power D, 2002, "Cultural industries in Sweden: an assessment of their place in the Swedish economy" Economic Geography 78 103-127

Power D, 2003, "The Nordic cultural industries: a cross-national assessment of the place of the cultural industries in Denmark, Finland, Norway and Sweden" Geografiska Annaler B 85 167180

Power D, Hallencreutz D, 2002, "Profiting from creativity? The music industry in Stockholm, Sweden and Kingston, Jamaica" Environment and Planning A 34 1833-1854

Power D, Hallencreutz D, 2007, "Competitiveness, local production systems and global commodity chains in the music industry: entering the US market" Regional Studies 41 377-389

Scott A, 1999, "The US recorded music industry: on the relations between organization, location, and creativity in the cultural economy" Environment and Planning A 31 1965-1984

Scott J, 2013 Social Network Analysis (SAGE, London)

Simonton D, 2004, "Group artistic creativity: creative clusters and cinematic success in feature films" Journal of Applied Social Psychology 34 1494-1520

Statistics Finland, 2013, http://pxweb2.stat.fi/database/StatFin/databasetree_en.asp (accessed on 3.4.2013)

Teosto, 2012, "Musiikki tuo leivän aktiivisimmille musiikintekijöille" www.teosto.fi/teosto/uutiset/musiikki-tuo-leivän-aktiivisimmille-musiikintekijöille (accessed on 28.8.2013)

Ter Wal A, Boschma R, 2009, "Applying social network analysis in economic geography: framing some key analytic issues" Annals of Regional Science 43 739-756 
Thorsby D, 2002 The Music Industry in the New Millennium: Global and Local Perspectives (UNESCO, Paris)

Tolppanen E, Tuomainen T, 2012 Musiikkialan Talous Suomessa 2011 (Music Finland, Helsinki)

VAKA, 2011 Valtakunnallisen Klubi- ja Aluekiertuehanke VAKAn Loppuraportti (Suomen Muusikkojen Liitto, Helsinki)

Watson A, 2008, "Global music city: knowledge and geographical proximity in London's recorded music industry" Area $\mathbf{4 0}$ 12-23

Watson A, 2012, "The world according to iTunes: mapping urban networks of music production" Global Networks 12 446-466

Watson A, Hoyler M, Mager C, 2009, "Spaces and networks of musical creativity in the city" Geography Compass 3 856-878

Watts D, Strogatz S, 1998, "Collective dynamics of 'small-world' networks" Nature 393 440-442

Williamson J, Cloonan M, 2007, "Rethinking the music industry" Popular Music 26 305-322 
FIGURES

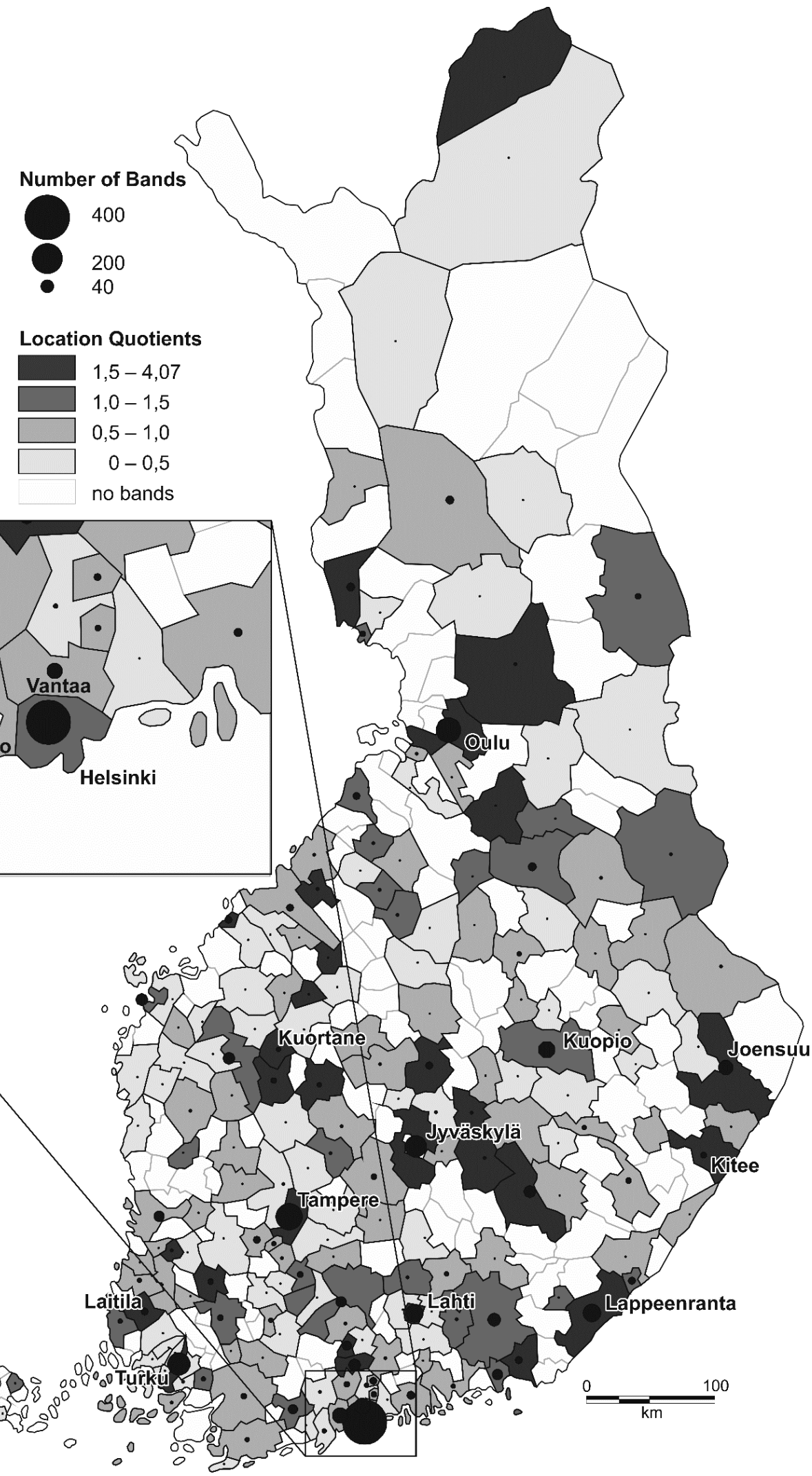

Figure 1. Number of metal bands in and location quotients of Finnish municipalities (Data sources:

Encyclopaedia Metallum, 2013; Statistics Finland, 2013; cartogram by Arttu Paarlahti) 


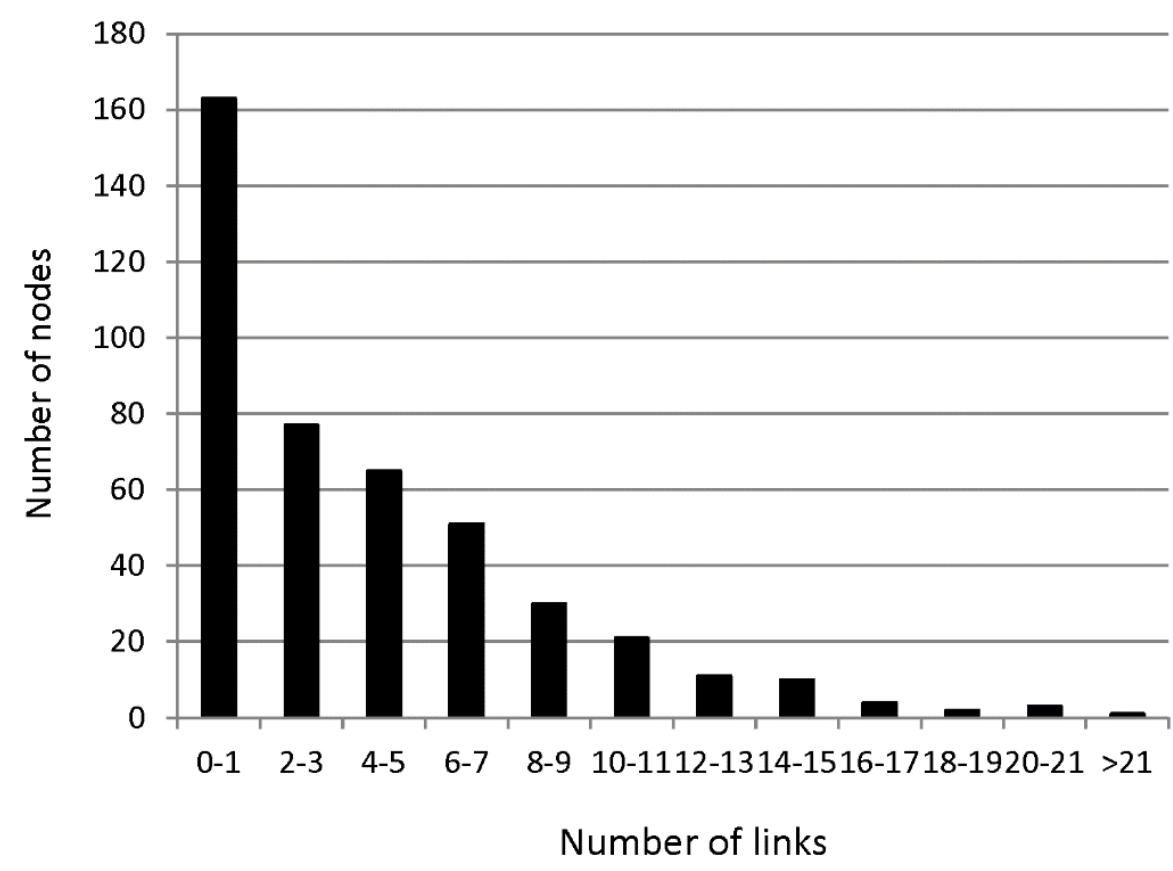

Figure 2. Distribution of the number of links in the network of metal bands in Helsinki 


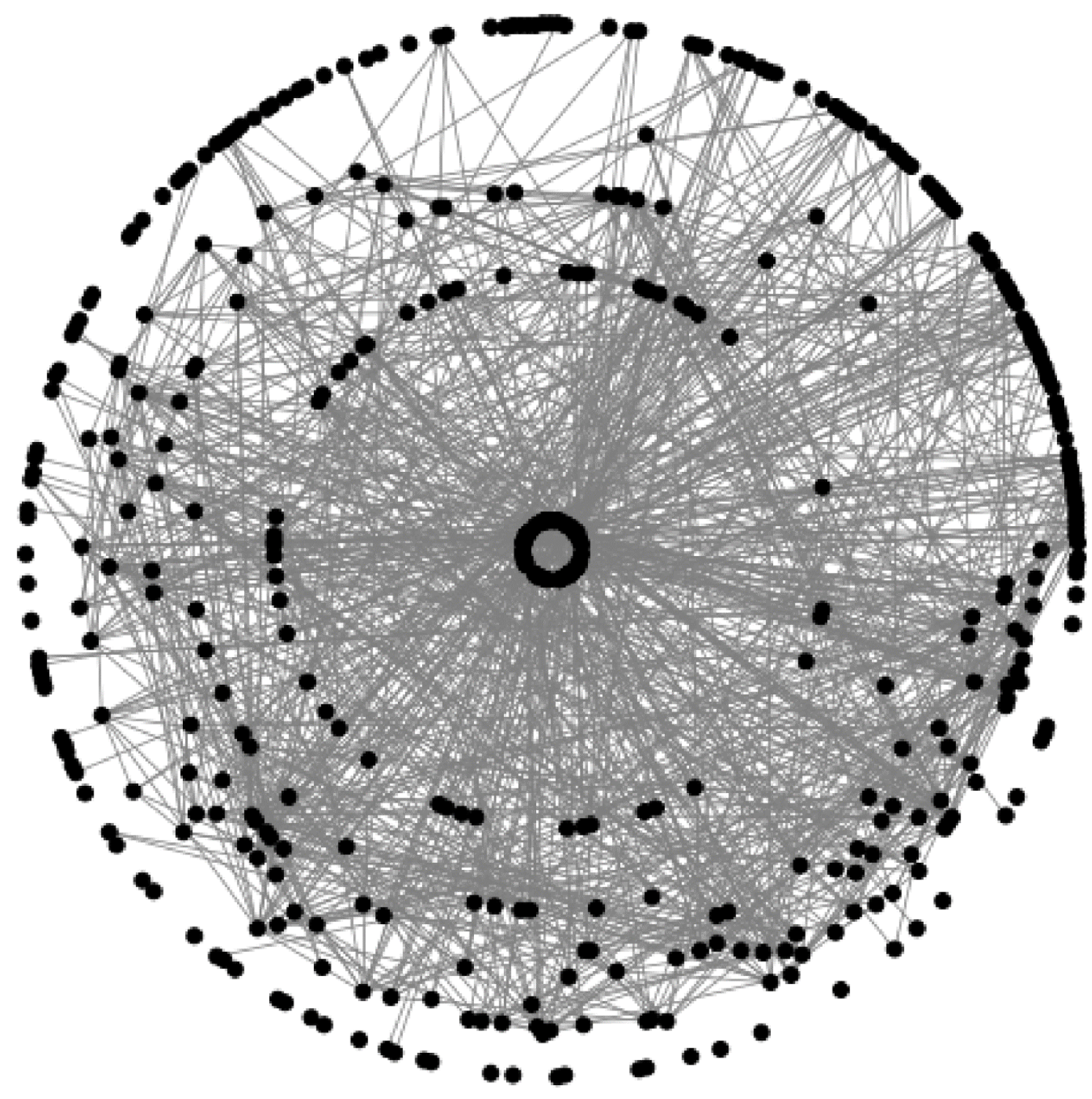

Figure 3. Structure of the network of metal bands in Helsinki 
Henri Sorvali, Marko Tarvonen and Janne Perttilä link

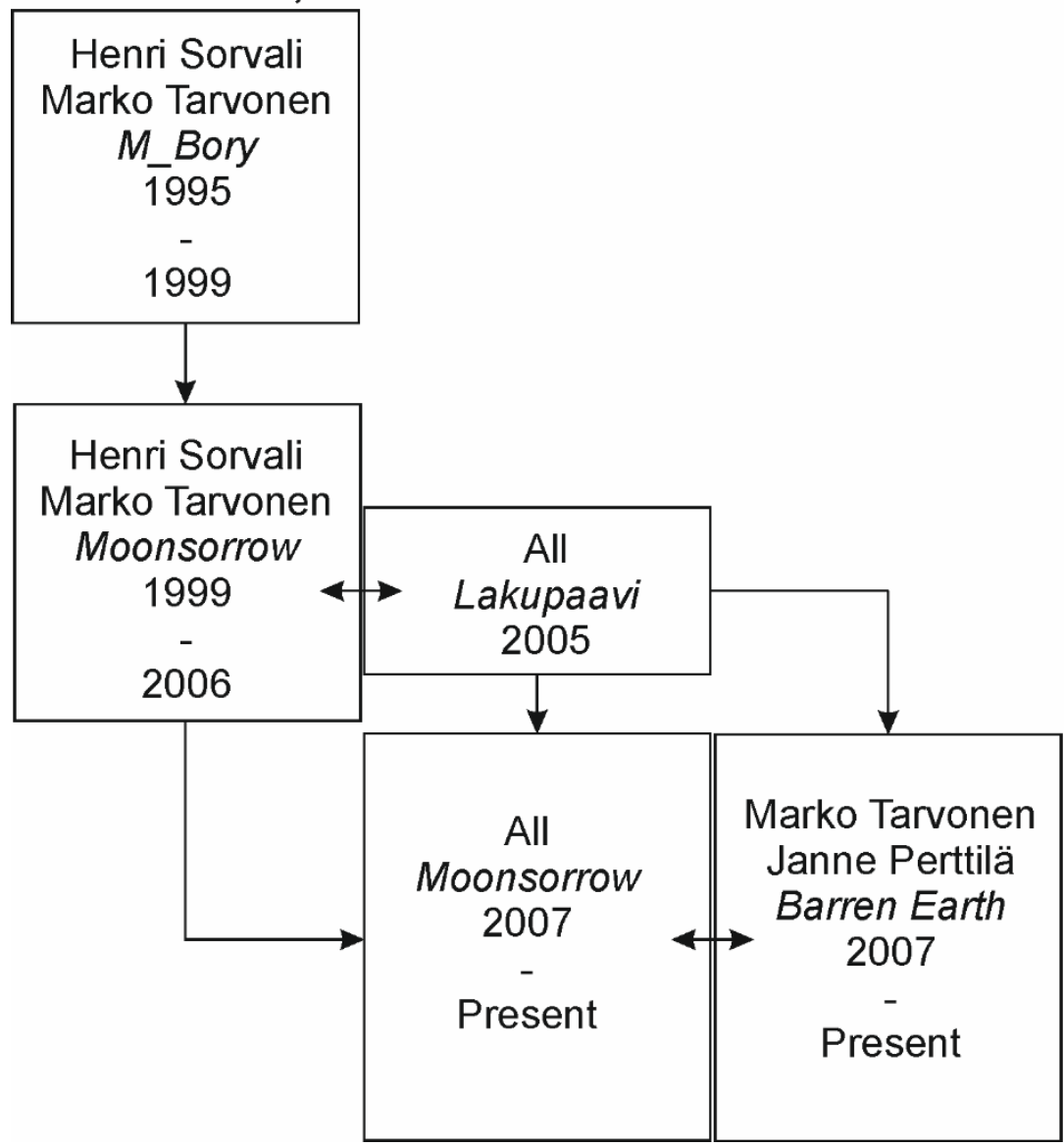

Figure 4. Joint-career path of the most connected individuals of the metal music network of Helsinki 